\title{
Hepatocellular carcinoma related to attempt of fertilization: A case report
}

\author{
Marcus PF Amarante ${ }^{1}$, Renata D Peixoto ${ }^{1}$, Marcos Belotto ${ }^{2}$, Marcelo RS Cruz ${ }^{* 1}$ \\ ${ }^{1}$ Clinical Oncology Department, Antônio Ermírio de Moraes Cancer Centre, Beneficência Portuguesa, São Paulo, Brazil \\ ${ }^{2}$ Surgical Oncology Department, Antônio Ermírio de Moraes Cancer Centre, Beneficência Portuguesa, São Paulo, Brazil
}

Received: August 31, 2015

Accepted: October 7, $2015 \quad$ Online Published: October 15, 2015

DOI: $10.5430 /$ crcp.v3n1p1

URL: http://dx.doi.org/10.5430/crcp.v3n1p1

\begin{abstract}
Hepatocellular carcinoma (HCC) is the most common malignant neoplasm of the liver, with approximately $10 \%-20 \%$ of the cases occurring in the non-cirrhotic liver. Hepatic adenomas (HA) are benign liver neoplasms, which arise predominantly in the setting of excess hormone exposure. The vast majority of HA have been reported in reproductive age women with a history of oral contraceptive pill therapy. In vitro fertilization (IVF) is a medical procedure in which the ovaries are stimulated by a combination of fertility medications and then one or more oocytes are aspirated from ovarian follicles. We report the case of a 33-year-old woman who presented with HCC after two attempts of fertilization. The patient had no virus B or C previous history, non-cirrhotic liver and was submitted to two human assisted reproductive procedures. No previous screening images had been performed before the fertilization attempt. Conclusions: The high hormone exposure in the setting of fertilization might have played a central role in the development of HCC. Furthermore, patients that are planning to perform fertilization are strongly advised to screen for HA in order to avoid malignant transformation to HCC.
\end{abstract}

Key Words: Hepatocellular carcinoma, Fertilization, Hormone exposure

\section{INTRODUCTION}

Hepatocellular carcinoma (HCC) is the most common malignant neoplasm of the liver and accounts for the third leading cause of cancer-related death worldwide. ${ }^{[1]}$ Almost 80 percent of HCC cases are due to underlying chronic hepatitis $\mathrm{B}$ (HBV) and C (HCV) virus infection, especially in the setting of liver cirrhosis. ${ }^{[2]}$ Other important risk factors for HCC are alcohol use and non-alcoholic steatohepatitis. ${ }^{[2]}$ However, approximately $10 \%-20 \%$ of the cases occur in the non-cirrhotic liver. ${ }^{[3,4]}$

Hepatic adenomas (HA) are benign liver neoplasms, which arise predominantly in the setting of excess hormone exposure, such as use of oral contraceptives, anabolic androgens, and glycogen storage disease. The vast majority of hepatic adenomas have been reported in reproductive age women with a history of oral contraceptive pill therapy and an otherwise normal appearing liver. The mechanism by which estrogen therapy contributes to the development of hepatic adenomas is poorly understood. Three small studies reported the development of malignant transformation in 8 to 17 percent of patients, suggesting that transformation into HCC is not a rare occurrence. ${ }^{[5]}$

In vitro fertilization (IVF) is a medical procedure in which the ovaries are stimulated by a combination of fertility medications and then one or more oocytes are aspirated from ovarian follicles. These are fertilized in the laboratory and

\footnotetext{
*Correspondence: Marcelo RS Cruz; Email: marcelo.cruz.md@gmail.com; Address: Clinical Oncology Department, Antônio Ermírio de Moraes Cancer Centre, Beneficência Portuguesa, São Paulo, Brazil.
} 
one or more embryos are transferred into the uterine cavity. The most common ovarian stimulators are gonadotropinreleasing $(\mathrm{GnRH})$ agonists. When stimulation begins, human menopausal gonadotropin (hMG) is administered in a dose of 225 to $300 \mathrm{IU} /$ day subcutaneously to stimulate follicular growth, with the GnRH agonist being continued at a lower dose to prevent a premature surge in luteinizing hormone (LH) secretion. The hMG dose is subsequently adjusted according to follicular growth (as determined by transvaginal ultrasonography) and serum estradiol concentrations (an indicator of granulosa cell proliferation). ${ }^{[6]}$

We report the case of a young woman who presented with HCC after two attempts of fertilization. The short time between the hormone exposure in fertilization procedures and the development of hepatocellular carcinoma led us to the hypothesis that hormone load might have played a key role in the carcinogenesis of this tumor.

\section{Material AND Methods}

A 33-year-old female was diagnosed with premature ovarian failure. She had a history of hypothyroidism diagnosed one year before and was attempting to become pregnant for four years since she interrupted the use of oral contraceptives. In April 2011, she sought treatment in a fertilization clinic.

The patient was submitted to two human assisted reproduc- tive procedures IVF without success. She received the following medications: In August 2011 she used 5 ampoules of follicle stimulating hormone recombinant (FSHr) $450 \mathrm{IU}$ (total of 2,175 IU), 5ampoules of cetrorelix acetate $0.25 \mathrm{mg}$ (total $1.25 \mathrm{mg}$ ) and 01 ampoule of recombinant chorionic gonadotropin recombinant (CGr) $0.25 \mathrm{mg}$. In November 2013 she received 09 ampoules of growth hormone $(\mathrm{GH})$ 4 UI (total of $36 \mathrm{IU}$ ); 17 ampoules of FSH urinary (FSHu) 75UI (total of 1,275 IU); 4 ampoules of FSHu and LH 75/75 IU (total 300 UI); 4 ampoules of FSHr 450 IU (total 1,500 $\mathrm{IU})$ and 1 ampoule of CGr $0.25 \mathrm{mg}$.

\section{RESUlts}

Within an interval of 30 months after the initial attempt and 3 months after the second, the patient presented with acute nausea and vomiting which led her to seek medical attention at an emergency room. A computed tomography (CT) of the abdomen showed an $11.8 \mathrm{~cm} \times 10 \mathrm{~cm}$ liver mass. A MRI of the abdomen showed an $11 \mathrm{~cm}$ encapsulated hepatic mass in segment VI with washout in the late stages and with foci of fat inside (see Figure 1). The mass compressed the duodenal arcade, the uncinated process of the pancreas, the right kidney and the inferior vena cava. Laboratory tests revealed an elevated alpha-fetoprotein (AFP) of 2,200 $\mathrm{ng} / \mathrm{ml}$, while serology for both HBV and HCV were negative.

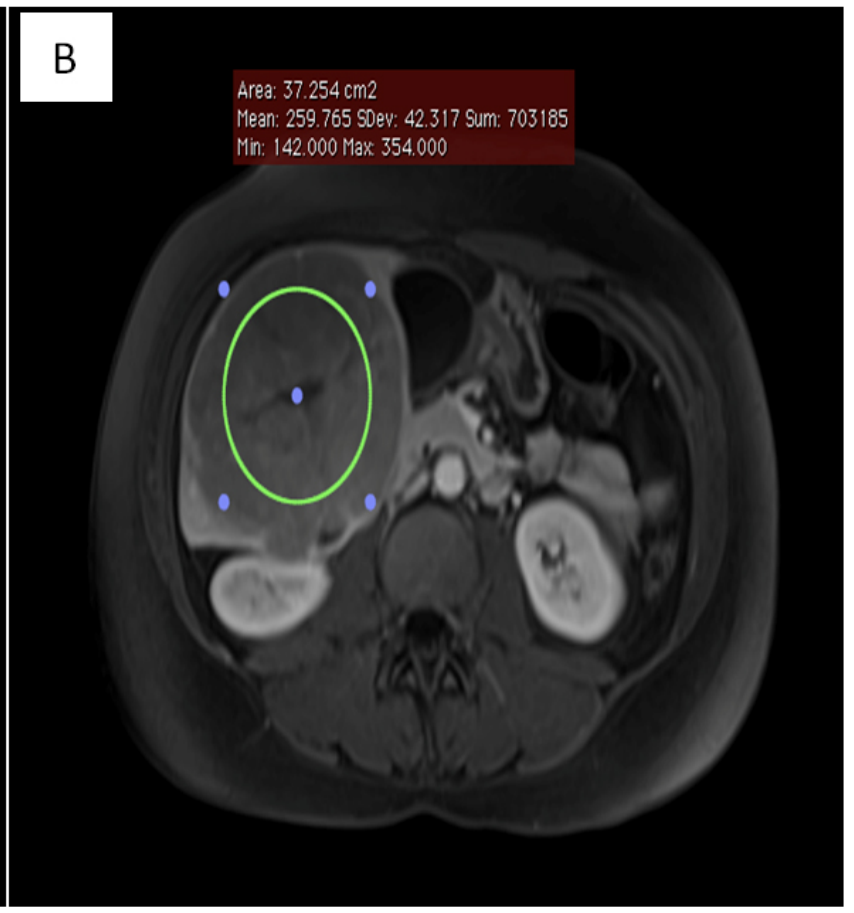

Figure 1. Expansive liver formation showing enhancement in arterial phase (A) and washout in the late stages (B) 
She underwent liver trisegmentectomy and pathology of the surgical specimen was consistent with hepatocellular carcinoma measuring $17 \mathrm{~cm}$ with angiolymphatic invasion and negative margins (see Figure 2). The immunohistochemistry was consistent with well-differentiated hepatocellular carcinoma (grade I) Hep-par weak positive; Collagen IV positive; CK7 positive; CD34 positive; AML positive and AE1/AE3 positive. New AFP levels after surgery was $256 \mathrm{ng} / \mathrm{ml}$.

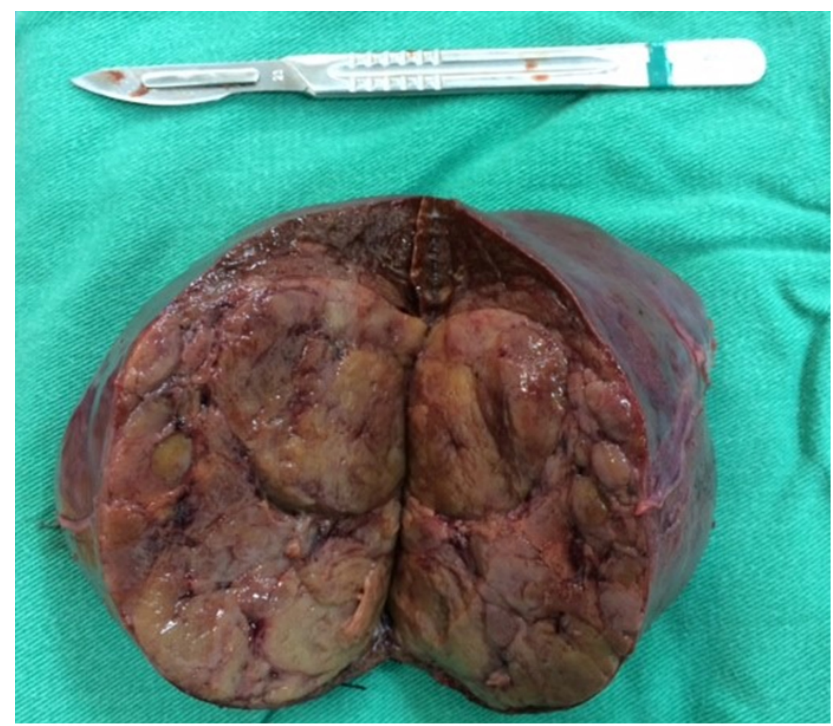

Figure 2. Product of hepatectomy showing a large hepatic mass

One month later the patient presented an episode of abdominal pain due to the rupture of the left ovary. A left oophorec- tomy was performed and the pathological examination was consistent with malignancy in the ovary measuring $5.0 \mathrm{~cm}$. The immunohistochemistry showed a poorly differentiated carcinoma compatible with hepatocellular carcinoma. At that time, AFP was $121 \mathrm{ng} / \mathrm{ml}$. Restaging image exams showed multiple lung nodules and liver lesions.

Before starting systemic therapy, the patient had an episode of generalized tonic-clonic seizure. She was admitted to the emergency room. Brain MRI showed a solid expansive mass in the cortico-subcortical right middle frontal gyrus with heterogeneous contrast uptake, measuring approximately $2.4 \mathrm{~cm}$ $\times 2.1 \mathrm{~cm} \times 2.4 \mathrm{~cm}$. The lesion was surrounded by an area of vasogenic edema. The patient underwent resection of the single brain metastasis followed by fractionated stereotactic radiotherapy to the surgical bed with a total dose of $25 \mathrm{G}$.

In June 2014, after the neurosurgery, she was started on systemic treatment with sorafenib $400 \mathrm{mg}$ BID. Response assessment was performed after 2 months of therapy and showed marked disease progression in liver and lungs. Second line treatment with gemcitabine $1,000 \mathrm{mg} / \mathrm{m}^{2}$ on D1 and oxaliplatin $100 \mathrm{mg} / \mathrm{m}^{2}$ on D2 every 2 weeks was introduced and partial response superior to $90 \%$ was obtained after 12 cycles (see Figure 3). Last follow up AFP level (March 2015) was $2.45 \mathrm{mg} / \mathrm{dl}$.

Next generation sequencing (NGS) test (Foundation Medicine, Cambridge, MA, USA) was performed and showed PTEN loss as a therapeutic target and suggested everolimus as a possible future treatment option.
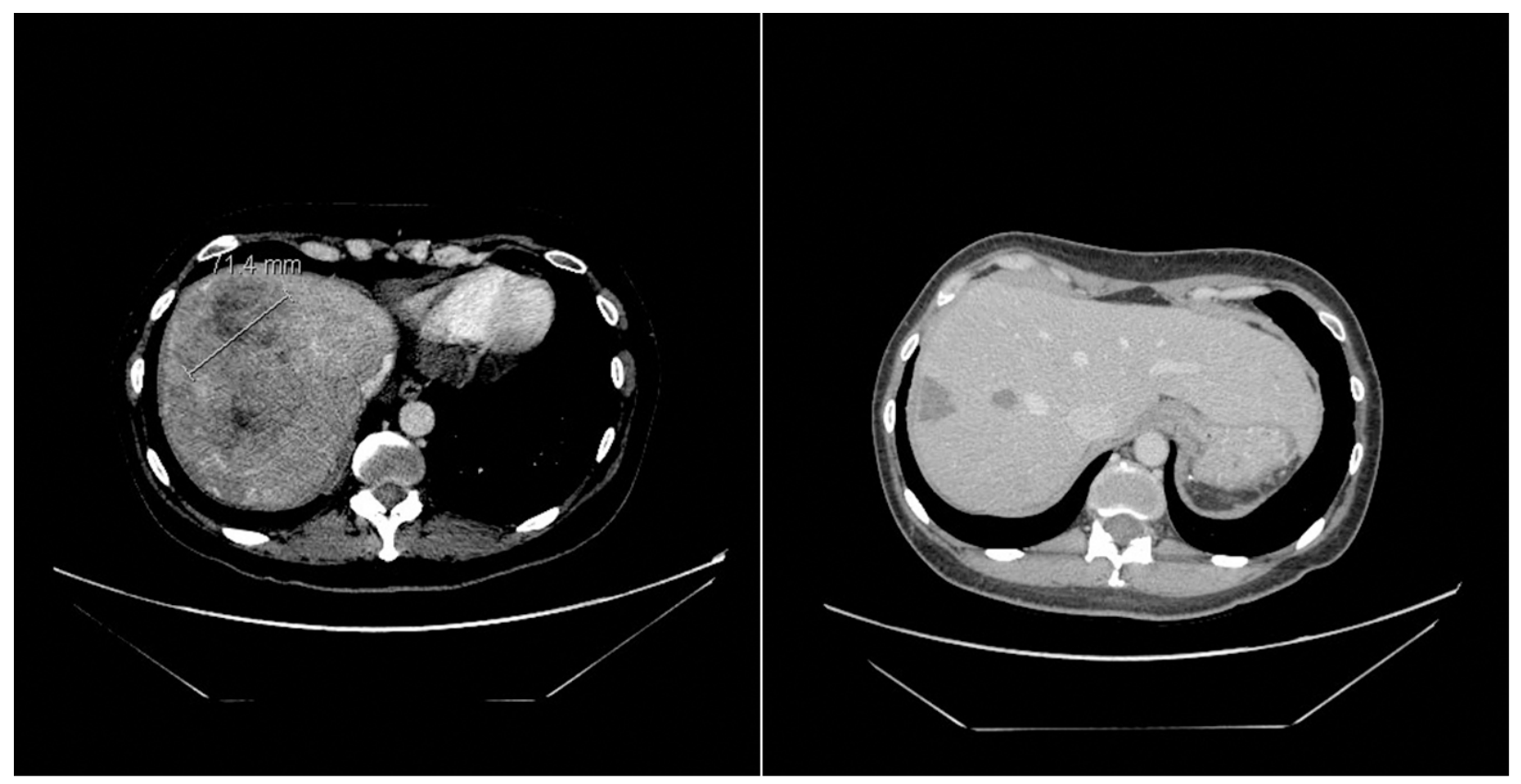

Figure 3. Abdomen CT showing important reduction of hepatic lesions after 12 cycles of GEMOX 


\section{Discussion}

The liver is intensely modulated by sex hormones. Long-term use of oral contraceptives as well as exposure to endogenous estrogen and anabolic androgenic steroids can induce both benign and malignant tumors. ${ }^{[7]}$ Differential expression of estrogen receptor (ER) and androgen receptor (AR) has been reported in both normal liver and HCC, suggesting a causal relation between sex hormones and pathogenesis of HCC. ${ }^{[8]}$ Epidemiologic and animal studies have suggested that men have a higher incidence of HCC than women which might be explained by stimulatory effects of androgen and the protective effects of estrogen. ${ }^{[9]}$

Babu and coworkers had formerly demonstrated a direct relationship between alpha fetoprotein (AFP) and the duration of oral contraceptive use. ${ }^{[10]}$ More recently, estrogen has been proven to exert protective effects against HCC through IL-6 restrictions, STAT3 inactivation and tumor-associated macrophage inhibition. ${ }^{[11]}$ Estrogen is involved in the regulation of the inflammation network in HCC by restraining of proinflammatory cytokines and inhibiting downstream signaling pathways. However, there is still controversy about the role of estrogen in HCC, since it has been also reported that estrogen may promote hepatocytes proliferation. ${ }^{[12]} \mathrm{A}$ meta-analysis of observational epidemiological studies was inconclusive to stablish a relation between oral contraceptives and the risk of hepatocellular carcinoma. ${ }^{[13]} \mathrm{A}$ recent study with 799,500 women showed that there was no association between oral contraceptives (OC) use and HCC risk. $^{[14]}$

HAs are essentially benign liver tumors that occur predominantly in young women taking oral contraceptives. Furthermore, intake of oral contraceptives could potentially play a role in the enlargement of existing HAs. However, the prevalence of malignancy within HAs is much more frequent in men than in women and seems to be associated with metabolic syndrom. ${ }^{[15]}$ High-risk groups for malignant transformation include patients with a history of androgen or anabolic steroid intake, male gender and patients with glycogen storage disease. A recent systematic literature review showed that malignant transformation of HAs into HCCs is a rare phenomenon with a frequency of $4.2 \% .^{[16]}$

The imaging modalities used for the diagnosis of HA include abdominal ultrasound, $\mathrm{CT}$ and magnetic resonance imaging. A percutaneous liver biopsy is controversial because the his- tology is often non-diagnostic and the procedure carries the risk of acute hemorrhage. ${ }^{[17]}$ If the clinical suspicion of hepatic adenoma or focal nodular hyperplasia is strong, elective laparotomy for diagnosis is usually the best approach. ${ }^{[18]}$

The CTNNB1 gene encodes for $\beta$-catenin which is a key molecule in the Wnt signaling pathway. ${ }^{[19]}$ HAs with $\beta$ catenin mutations represents $10 \%-15 \%$ of all HAs and are related to malignant differentiation to HCC. ${ }^{[20]}$ This corroborates with the findings that $\beta$-catenin activation is a frequent (20\%-34\% of cases) event in HCCs. ${ }^{[21]}$ As such, the CTNNB1 gene may represent an oncogene in the natural history of progression from HA to HCC. HAs with $\beta$-catenin mutation are more likely to progress to HCC (up to 50\%), making $\beta$-catenin activation as a surrogate high-risk marker for HCC progression. ${ }^{[16]}$

$\mathrm{GH}$ is an important regulator of body growth and its receptor (GHR) is widely expressed in many tissues such as liver, muscle and adipose tissue. GHR activation is responsible by multiple signaling pathways, including the RAS/RAF/ERK, the PI3K and the JAK/STAT. ${ }^{[22]}$

In the liver, GH binds GHR, which results in the activation of JAK2, which in turn phosphorylates the signal transducer and activator of transcription 5 (STAT5). GH-STAT5 signaling controls expression of target genes associated with several physiological processes. ${ }^{[23]}$ STAT5 activity in hepatocytes was suggested to stimulate cell cycle arrest upon chronic hepatocyte injury, while loss of STAT5 signaling favors activation of pro-survival and proliferation pathways. ${ }^{[22]}$

In the reported case, no previous screening images had been performed before the fertilization attempt in order to detect possible previous existing HAs. The high hormone exposure in the setting of fertilization might have played a central role in the development of HCC. Unfortunately, we have no data regarding the blood hormone levels of patient and AFP levels in a way of direct comparison to stablish a stronger relationship between them.

The use of GH in the second fertilization attempt and the short time between GH exposure and the onset of symptoms led us to the hypothesis that exposure to $\mathrm{GH}$ in a patient with otherwise previously disrupted STAT5 signaling may have strongly contributed to such an aggressive form of HCC. The NGS test finding of PTEN loss, a mediator of PI3K pathway reinforces this hypothesis. 


\section{REFERENCES}

[1] Fares N, Péron J-M. Epidemiology, natural history, and risk factors of hepatocellular carcinoma. Rev Prat. 2013; 63(2): 216-217, 220-222. PMid: 23513788.

[2] Fehér J, Lengyel G. Hepatocellular carcinoma: occurrence, risk factors, biomarkers. Orv Hetil. 2010; 151(23): 933-940. http: //dx.doi.org/10.1556/0H.2010.28900

[3] Evert M, Dombrowski F. Hepatocellular carcinoma in the noncirrhotic liver. Pathologe. 2008; 29(1): 47-52. http://dx.doi .o $\mathrm{rg} / 10.1007 / \mathrm{s} 00292-007-0953-3$

[4] Trevisani F, Frigerio M, Santi V, et al. Hepatocellular carcinoma in non-cirrhotic liver: a reappraisal. Dig Liver Dis. 2010; 42(5): 341-347. http://dx.doi.org/10.1016/j.dld.2009.09.002

[5] Micchelli STL, Vivekanandan P, Boitnott JK, et al. Malignant transformation of hepatic adenomas. Mod Pathol. 2008; 21(4): 491-497. http://dx.doi.org/10.1038/modpathol.2008.8

[6] Fertility treatment options (e.g., ovulation induction, IVF) - Fertility - Body \& Health. Available from: http://bodyandhealth. cana da.com/channel_section_details . asp?text_id=6426\&c hannel_id=2048\&relation_id=109655. Accessed April 10, 2015.

[7] Giannitrapani L, Soresi M, La Spada E, et al. Sex hormones and risk of liver tumor. Ann N Y Acad Sci. 2006; 1089: 228-236. http://dx.doi.org/10.1196/annals.1386.044

[8] Kalra M, Mayes J, Assefa S, et al. Role of sex steroid receptors in pathobiology of hepatocellular carcinoma. World J Gastroenterol. 2008; 14(39): 5945-5961. PMid: 18932272. http://dx.doi.org /10.3748/wjg.14.5945

[9] Yeh S-H, Chen P-J. Gender disparity of hepatocellular carcinoma: the roles of sex hormones. Oncology. 2010; 78 Suppl 1: 172-179. http://dx.doi.org/10.1159/000315247

[10] Babu S, Ramalakshmi BA, Prema K. Plasma alpha-feto protein levels and its relation to duration of oral contraceptive use. Contraception. 1980; 21(1): 53-60. http://dx.doi.org/10.1016/0010-7 824(80) 90139-0

[11] Shi L, Feng Y, Lin H, et al. Role of estrogen in hepatocellular carcinoma: is inflammation the key? J Transl Med. 2014; 12: 93. http: //dx . doi .org/10.1186/1479-5876-12-93

[12] Kalaitzidis D, Gilmore TD. Transcription factor cross-talk: the estrogen receptor and NF-kappaB. Trends Endocrinol Metab. 2005; 16(2): 46-52. http://dx.doi.org/10.1016/j.tem. 2005.01.004

[13] Maheshwari S, Sarraj A, Kramer J, et al. Oral contraception and the risk of hepatocellular carcinoma. J Hepatol. 2007; 47(4): 506-513. http://dx.doi.org/10.1016/j.jhep. 2007.03.015
[14] McGlynn KA, Sahasrabuddhe VV, Campbell PT, et al. Reproductive factors, exogenous hormone use and risk of hepatocellular carcinoma among US women: results from the Liver Cancer Pooling Project. $\mathrm{Br}$ J Cancer. 2015; 112(7): 1266-1272. http://dx.doi.org/10.10 $38 /$ bjc. 2015.58

[15] Farges O, Ferreira N, Dokmak S, et al. Changing trends in malignant transformation of hepatocellular adenoma. Gut. 2011; 60(1): 85-89. http://dx.doi.org/10.1136/gut.2010.222109

[16] Stoot JHMB, Coelen RJS, De Jong MC, et al. Malignant transformation of hepatocellular adenomas into hepatocellular carcinomas: a systematic review including more than 1600 adenoma cases. HPB (Oxford). 2010; 12(8): 509-522. http://dx.doi.org/10.1111 /j.1477-2574.2010.00222.x

[17] Kim DH, Kim SU, Nam DH, et al. A Case of Hepatocellular Carcinoma Within Hepatocellular Adenoma in a Non-Cirrhotic Male. Korean J Intern Med. 2009; 24(2): 147-152. http://dx.doi .org /2009.24.2.147

[18] Kerlin P, Davis GL, McGill DB, et al. Hepatic adenoma and focal nodular hyperplasia: clinical, pathologic, and radiologic features. Gastroenterology. 1983; 84(5 Pt 1): 994-1002. PMid: 6299876.

[19] Nhieu JT, Renard CA, Wei Y, et al. Nuclear accumulation of mutated beta-catenin in hepatocellular carcinoma is associated with increased cell proliferation. Am J Pathol. 1999; 155(3): 703-710. http: //dx .doi.org/10.1016/S0002-9440(10)65168-1

[20] Khanna M, Ramanathan S, Fasih N, et al. Current updates on the molecular genetics and magnetic resonance imaging of focal nodular hyperplasia and hepatocellular adenoma. Insights Imaging. 2015; 6(3): 347-362. http://dx.doi.org/10.1007/s13244-015-0 399-8

[21] Miyoshi Y, Iwao K, Nagasawa Y, et al. Activation of the beta-catenin gene in primary hepatocellular carcinomas by somatic alterations involving exon 3. Cancer Res. 1998; 58(12): 2524-2527. PMid: 9635572

[22] Mueller KM, Themanns M, Friedbichler K, et al. Hepatic growth hormone and glucocorticoid receptor signaling in body growth, steatosis and metabolic liver cancer development. Mol Cell Endocrinol. 2012; 361(1-2): 1-11. http://dx.doi.org/10.1016/j.mce.2012.03 .026

[23] Baik M, Yu JH, Hennighausen L. Growth hormone-STAT5 regulation of growth, hepatocellular carcinoma, and liver metabolism. Ann N Y Acad Sci. 2011; 1229: 29-37. http://dx.doi.org/10.1111/j $.1749-6632.2011 .06100 . x$ 